\title{
PERSONAS REALES Y JUSTICIA POÉTICA: LOPE, GUILLÉN DE CASTRO, ROJAS ZORRILLA*
}

\author{
FELIPE B. PEDRAZA JIMÉNEZ \\ Universidad de Castilla-La Mancha
}

\section{CUATRO COMEDIAS TRÁGICAS Y SUS FECHAS}

Me propongo analizar cuatro comedias trágicas de nuestro Siglo de Oro que presentan un conflicto extremo en el que el monarca tiene que impartir justicia contra su propio hijo, heredero de la corona, acusado de asesinato.

La primera de estas piezas, El marqués de Mantua de Lope de Vega, se acabó de redactar, según el manuscrito Gálvez, el 10 de enero de 15961', es decir, hacia el final de lo que la crítica viene considerando la primera etapa de la dilatada trayectoria del dramaturgo, poco antes de la suspensión de las representaciones en 1597, a raíz de la muerte de Catalina de Saboya; y antes de que el autor fijara el primer catálogo de sus obras en los preliminares de $E l$

\footnotetext{
* Este trabajo es fruto de la investigación en torno a Rojas Zorrilla que viene desarrollando el Instituto Almagro de teatro clásico. Se incluye dentro del proyecto Rojas Zorrilla ante la crítica (PAI06-0023), aprobado y subvencionado por la Consejería de Educación y Ciencia de la Junta de Comunidades de Castilla-La Mancha.

1 Véase Agustín G[onzález] de Amezúa y Mayo, “Una colección manuscrita y desconocida de comedias de Lope de Vega", Madrid, 1945; reimpreso en Opúsculos histórico-literarios, II, Madrid, CSIC, 1951, pp. 364-417.
} 
peregrino en su patria (1604). Se publicó en la Parte docena de las comedias de Lope (1619).

La segunda en el tiempo es La justicia en la piedad de Guillén de Castro. Bruerton, siguiendo el método de las estadísticas métricas que tan buen resultado dio en el caso de Lope de Vega, señaló como fecha posible de redacción la de 1615?-20?2 . Es decir, se crea unos veinte años después que El marqués de Mantua y en las postrimerías del reinado de Felipe III. Se publicó en la Segunda parte de comedias de Guillén de Castro (Madrid, 1625), con el título que utilizamos en nuestro estudio, y en la Parte veinte y seis de comedias nuevas escogidas de los mejores ingenios de España (Madrid 1666), con los elementos del rótulo invertidos: La piedad en la justicia. Bajo esta denominación se reeditó en la "Biblioteca de autores españoles" 3.

Las otras dos tragedias pertenecen a Francisco de Rojas Zorrilla y se crearon en lo que hemos llamado la década de oro de la comedia española. No hay ser padre siendo rey la representó la compañía de Antonio de Prado el 1 de enero de 1635 en el palacio real. Se conserva un manuscrito incompleto de 1635 (BNE, ms. 15758). Sobre El Caín de Cataluña tenemos menores precisiones, pero es indudable que se escribió en fechas muy próximas, en todo caso antes del 6 de octubre de 1644, en que la muerte de la reina Isabel de Borbón determinó el cierre de los teatros. Sí contamos con noticias sobre escenificaciones póstumas. El ms. 14439 de la BNE contiene las notas de censura de 1678. Sabemos también que se representó en palacio en 1685 , en Valladolid en 1687 y profusamente a lo largo del siglo XVIII ${ }^{4}$.

Unos cuarenta años separan El marqués de Mantua y las dos tragedias de Rojas Zorrilla: desde el final del reinado de Felipe II al momento central del poder del conde-duque de Olivares. Mi hipótesis es que esas circunstancias históricas y las teorías políticas del momento no son ajenas al desarrollo dramático y, sobre todo, a la resolución final del conflicto ${ }^{5}$.

\footnotetext{
2 Courtney Bruerton, "The chronology of the Comedias of Guillén de Castro", Hispanic Review, XII (1944), pp. 89-151.

3 Dramaturgos contemporáneos de Lope de Vega, tomo I, ed. de Ramón de Mesonero Romanos, "Biblioteca de autores españoles", núm. 43, Madrid, Ribadeneyra, 1857.

4 Véase Ann L. Mackenzie, Francisco de Rojas Zorrilla y Agustín Moreto. Análisis, Liverpool University Press, 1994, p. 52, que resume las noticias allegadas por Shergold y Varey, Alonso Cortés, Sureda, Juliá, Montero de la Puente, Aguilar Piñal y Par.

5 Para evitar constantes remisiones a las notas de pie de página, en el caso de las obras dramáticas señalaré junto al texto la página o los versos correspondientes. El marqués de Mantua lo cito por la edición de Jesús Gómez y Paloma Cuenca (Lope de Vega, Comedias, V, Madrid, Turner, 1993); a pesar de sus notables deficiencias, es el impreso más accesible en este momento (el único que está en el mercado). Para La justicia en la piedad utilizaré la edición de Eduardo Juliá Martínez (Guillén de Castro, Obras, III, Madrid, Real Academia Española, 1927), que, por cierto, no se aclara con el título y alterna sin razón aparente La justicia en la piedad y La piedad en la justicia. No hay ser padre
} 


\section{PARALELISMOS y CONTRASTES ARGUMENTALES: EL MARQUÉS DE MANTUA}

Recordemos las líneas maestras de la acción. En El marqués de Mantua, una de las más hermosas tragedias del primer Lope, se nos presenta la boda de Valdovinos con la princesa mora Sevilla. El príncipe Carloto, primogénito y heredero de Carlomagno, se enamora perdidamente de la novia (como Tello en El mejor alcalde, el rey, o el comendador de Ocaña en Peribáñez); pide consejo al traidor Galalón:

\section{GALALÓN. Pues respondo que le escondas dentro del alma ese acero; que, si no es estando muerto Valdovinos, no hay lugar de que la puedas gozar por fuerza ni por concierto.}

(El marqués de Mantua, p. 297)

La decisión está tomada al acabar el primer acto; el segundo se dedica a la puesta en obra del siniestro plan; y el tercero, a la demanda de justicia por los deudos de Valdovinos y la resolución justiciera de Carlomagno que desemboca en la ejecución del heredero de la corona.

\section{LA JUSTICIA EN LA PIEDAD}

El mismo problema básico, pero con distinto tono y solución, lo encontramos en La justicia en la piedad de Guillén de Castro. La acción se sitúa en Hungría, en un marco de convencional lejanía propio de la tragedia palatina. Sin embargo, es posible que la materia tuviera una vaga inspiración histórica, pues Lancaster señaló como fuente para No hay ser padre siendo rey de Rojas Zorrilla, que trata el mismo asunto, la Historia Bohemica de Dubravius (Hanar, $1609)^{6}$.

Frente al desnudo y directo drama de Lope, el de Guillén de Castro presenta un enrevesamiento y una sofisticación que, en mi concepto, enturbian

\footnotetext{
siendo rey la cito por la edición de Enrico Di Pastena (Francisco de Rojas Zorrilla, Obras, I, ed. del Instituto Almagro de teatro clásico, Cuenca, Universidad de Castilla-La Mancha, en prensa). Para El Caín de Cataluña recurro a la edición de Ramón de Mesonero Romanos (Francisco de Rojas Zorrilla, Comedias escogidas, "Biblioteca de autores españoles", núm. 54, Madrid, Ribadeneyra, 1861).

${ }^{6}$ H. C. Lancaster, "The ultimate source of Rotrou's Venceslas and of the Rojas Zorrilla's No hay ser padre siendo rey", Modern Philology, XV (Chicago, 1917-1918), pp. 435-440.
} 
un tanto sus méritos. El aspecto más problemático para la sensibilidad moderna es el carácter del rey. En la primera jornada aparece como un ser intemperante, odioso y criminal que esgrime los argumentos propios del tirano:

REY. $\quad \ldots$ ¿De qué sirviera

el serlo [rey], si no pudiera

hacer leyes con el gusto?

(La justicia en la piedad, p. 117b)

En esos primeros compases del drama lo vemos cometiendo tropelías, allanamientos, incluso un asesinato (el de Lotario, marido de Arcinda, dama de la que se ha encaprichado); pero, al percatarse del odio que engendra su actitud y sufrir los remordimientos que acompañan a su delito ("Aquel hombre que maté [...]/ como en sombras me atormenta/ con su sangre, p. 126b), se trasforma radicalmente y se convierte en un rey justiciero.

Para su desdicha, sus pésimas costumbres han pasado al heredero de la corona. El príncipe, enamorado de Celaura, no duda en allanar la finca en que la dama se ha refugiado, violarla y matar a su esposo Atislao. El arrepentimiento, aunque inmediato, llega tarde: "Ya estoy de lo que he hecho arrepentido" (p. 147a).

Al empezar el tercer acto, Celaura se presenta ante el rey, "sin chapines, con las manos y el rostro salpicado en sangre y un pañuelo y la daga del príncipe en la mano" (p. 148b). Pide justicia contra el asesino. Y deja clara su resolución amenazante: "Justicia espero o tomaré venganza" (p. 152a).

El delincuente es apresado y aparece en escena "con una cadena" y recitando versos que, sin duda, debieron de ser conocidos y saboreados por Calderón:

PRÍNCIPE. ¡Cielo, cielo poderoso! ¿Es soñado cuanto veo?

¿Presa la persona mía?

¿Yo cadenas? ¿No soy yo, por ventura, el que nació para heredero de Hungría?

(La justicia en la piedad, p. 152a)

Aun reconociendo su delito y el justiciero proceder del rey ("Mi padre es justo aunque mande/ que muchas muertes me den", p. 152b), alienta en él la esperanza de la impunidad: 


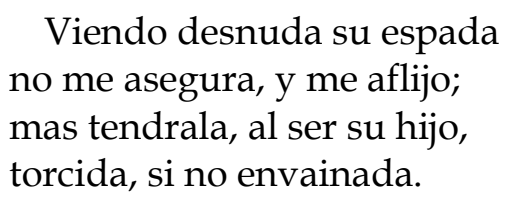

(La justicia en la piedad, p. 152b)

Como en El mejor alcalde, el rey de Lope (estrenada en fechas próximas a la redacción de La justicia en la piedad7), al príncipe se le exige que se case con Celaura e inmediatamente se le notifica la sentencia de muerte.

La recién desposada mantiene su rencor y su demanda contra su nuevo marido, que solo pide en tan duro trance:

PRÍNCIPE. $\quad$...perdóname tú, aunque el rey me castigue.

(La justicia en la piedad, p. 154a)

El monarca, en su firmeza y rigor, no deja de sentir una tribulación que aumenta con los ruegos y razones de la reina; pero no cede en su determinación. A la madre desconsolada se unen finalmente las súplicas de los ofendidos: la propia Celaura y su padre. Pese a todo, el soberano, retorciéndose el corazón, mantiene que "no han de ser padres los reyes" (p. 159a), verso del que saldría el título de la tragedia de Rojas Zorrilla.

Una rebelión popular impide el ajusticiamiento, con notable alegría del rey, que no atiende a los consejos de Feduardo, su valido:

FEDUARDO. Mira por ti; que aunque sea

tu hijo, contigo está enojado, es mozo y tiene en su punto la crueldad. [...]

REY. Vengan, vengan contra mí, pues cuando me apremien más, quedaré más disculpado; [...] alegre por restaurar su vida, daré la mía. (La justicia en la piedad, p. 159a-b)

Pero el príncipe, victorioso en alas de la revolución, también se ha trasformado:

\footnotetext{
7 Inmediatamente posteriores: 1620-1623, según S. Griswold Morley y Courtney Bruerton, Cronología de las comedias de Lope de Vega, Madrid, Gredos, 1968, p. 359.
} 
PRÍNCIPE. $\quad$...que vida ni libertad no quiero contra tu gusto...

(La justicia en la piedad, p. 159b)

El precipitado cierre del drama incluye la reconciliación con Celaura ("Mucho obligado me has,/ si mucho me has ofendido", p. 159b), lo que permite al rey pronunciar las palabras finales:

REY. Y aquí tiene alegre fin

La justicia en la piedad.

(La justicia en la piedad, p. 159b)

\section{DOS TRAGEDIAS GEMELAS}

Los dramas de Rojas, como corresponde al momento de su creación y a su particular concepción del fenómeno trágico, hacen aún más extrema y complicada la situación. Se ve que al poeta y a su público no les parecía bastante grave el asesinato de un tercero, ligado por lejanos lazos familiares, como en la tragedia de Lope. En No hay ser padre siendo rey y El Caín de Cataluña se trata de sendos fratricidios, para no dejar por mentirosa a la crítica que describe el teatro de Rojas como propenso al hiperdramatismo ${ }^{8}$.

Como en otros casos dentro de la obra de Rojas, estamos ante dos tragedias gemelas, con numerosos elementos en común y también -claro está - con sutiles diferencias entre la acción, los personajes, la solución..., de modo que no son solo dos piezas paralelas sino al mismo tiempo complementarias 9 .

\section{NO HAY SER PADRE SIENDO REY}

No hay ser padre siendo rey, que parece ser la primera en la redacción, se sitúa en la Polonia imaginaria que habían puesto de moda obras como Yerros de naturaleza y aciertos de la fortuna de Coello y Calderón y La vida es sueño; sin

\footnotetext{
8 Véanse las consideraciones sobre este punto en el interesante artículo de Teresa Julio, "Hiperdramatismo en Rojas Zorrilla: innovación o continuidad", en Felipe B. Pedraza, Rafael González Cañal y Elena Marcello (eds.), Francisco de Rojas Zorrilla, poeta dramático. XXII Jornadas de teatro clásico, 13, 14 y 15 de julio de 1999, Almagro, Universidad de Castilla-La Mancha, 2000, pp. 179-208.

${ }^{9}$ A estas dos tragedias podría añadirse El más impropio verdugo por la más justa venganza. Aunque se desarrolla entre caballeros particulares, presenta conflictos que, por su truculencia y extremismo, guardan cierta relación con las obras aquí examinadas.
} 
olvidar la novela Eustorgio y Clorilene. Historia moscóvica de Enrique Suárez de Mendoza. Nos presenta los constantes enfrentamientos entre Rugero, primogénito y heredero del reino, y su hermano Alejandro. En medio, un padre viejo y enfermo. El príncipe Rugero reúne maniqueamente todos los rasgos negativos:

REY. $\quad$...vos, todo entregado al vicio, al apetito y torpeza,

mal podréis vivir buen rey...

(No hay ser padre..., vv. 77-79)

Pese a tan nítida valoración, el viejo monarca se ve incapaz de corregir a su díscolo primogénito y trata de atraerlo con halagos y razonamientos.

En rigor, Rugero es un personaje contradictorio, que no logra reconciliarse consigo mismo ("si aun lo que quiero, no quiero", v. 497). Un conflicto amoroso (Rugero se enamora de la duquesa Casandra, secreta esposa de Alejandro) se une a otro político: el enfrentamiento con el valido, el duque Federico, al que el violento Rugero supone enamorado o amante de la primera dama.

Tras un enrevesado enredo de entradas y salidas, de mentiras y ocultaciones, de confusión de identidades (se podría hablar de una "tragedia de enredo", modalidad dramática no infrecuente en la generación calderoniana), el príncipe, cegado por los celos, mata al hombre que duerme en la cama de Casandra, creyendo que acaba con la vida del valido. El espectador sabe que el asesinato es, al mismo tiempo, un involuntario fratricidio.

Al empezar el acto tercero, el príncipe rememorará, acongojado, la escena del crimen. Se le aparece un bulto que dice ser Rugero y no es sino "un esqueleto sin forma" (v. 2246).

A partir de aquí, se plantea el mismo problema jurídico-político que en El marqués de Mantua. Asistimos al encarcelamiento del príncipe, en imagen que debía de resultar ya familiar a los espectadores de 1636: "Sale Rugero en la torre con prisiones". Casandra se persona como demandante; vuelve a rememorar la fatídica noche:

cuando a la calma de amor, el mar que estaba tranquilo en huracanes de sangre levanta penachos rizos.

(No hay ser padre..., vv. 2509-2512) 
Y advierte al rey de los peligros de la indulgencia:

Mira que, si le perdonas, buscas tu muerte tú mismo.

(No hay ser padre..., vv. 2615-2616)

La deuda de estas tragedias con El castigo sin venganza está clara en numerosas citas:

CASANDRA. Venganza pide el delito.

REY. No pienso tomar venganza, pero daréle castigo.

(No hay ser padre..., vv. 2726-2728)

Un patético diálogo sobreviene cuando el rey comunica a su hijo el dictamen, en el que no faltan los razonamientos jurídicos:

RUGERO. Al duque quise matar y erré su cobarde pecho [...].

REY. Pues que me habéis confesado una muerte en que incurristes, no os castigo a quién la distes, castígoos que la habéis dado. [...] y por el muerto os perdono, mas por la muerte os castigo.

(No hay ser padre..., vv. 2863-2882)

RUGERO. ....Siendo padre me castigas.

REY. No hay ser padre siendo rey.

(No hay ser padre..., vv. 3009-3010)

Como en el caso de El marqués de Mantua, no faltan las voces que invocan la razón de estado para pedir clemencia, ante la grave consecuencia de dejar "al reino sin heredero" (v. 3098). Los agraviados (Casandra y el duque) retiran los cargos y suplican el indulto. El rey se niega, hasta que una revuelta popular impide la ejecución. El viejo monarca abdica. 


\title{
6. EL CAÍN DE CATALUÑA
}

Estamos ante un drama historial, no una tragedia palatina como No hay ser padre siendo rey. El propio poeta lo señaló en las notas finales: “...este caso verdadero/tendrá más felice fin..." (p. 293c) ${ }^{10}$.

$\mathrm{Su}$ argumento tiene como fuente remota el asesinato de Ramón Berenguer por su hermano Berenguer Ramón en 1082. El fratricida es el conde barcelonés que aparece en el Cantar de Mio Cid como prisionero del héroe castellano.

En la acción del drama de Rojas todos los elementos históricos se disuelven en un marco legendario que autoriza a extremar y contraponer los caracteres en un juego maniqueo tan exacerbado que va más allá del contrapunto melodramático entre la bondad y la maldad y apunta hacia la expresión hiperbólica e irracional del insondable abismo de los celos y la envidia. MacCurdy analizó la figura de Berenguel: no le parece "a fully-realized character" porque "his creator has too obviously marked him for condemnation when the first appears upon the stage"11. Más comprensiva, Ann Mackenzie ha subrayado el sesgo agónico, la angustia existencial que corre por las venas del Berenguel de Rojas ${ }^{12}$. Se trata de un rebelde sin causa, en permanente conflicto con el mundo, envidioso perpetuo de su hermano, al que odia y persigue hasta la muerte. Como ocurre en los personajes de esta etapa de la comedia española, sorprende la lúcida conciencia con que describen sus almas torturadas. Berenguel sabe que, una vez tras otra, pisa "el áspid invisible de los celos" (p. 278b). Después del fratricidio se ve permanentemente acosado:

\author{
Todo el cielo me parece \\ que me amenaza, trasuda \\ el corazón, y sus alas \\ las abate y no las junta. \\ Esa montaña parece \\ que cae sobre mí, esas grutas
}

\footnotetext{
10 Años después, Francisco de Avellaneda, censor de la representación de 1678, subrayó ese mismo detalle: "Sr., he visto esta comedia de El Caín de Cataluña, y por caso verdadero..." (ms. 14439 de la BNE).Véase mi artículo "La musa histórica de Rojas Zorrilla: El caín de Cataluña", que se publicará en las actas del XVI Congreso de la Asociación de Hispanistas Alemanes (Dresde, 2831 de marzo de 2007).

${ }^{11}$ Raymond MacCurdy, Francisco de Rojas Zorrilla and the tragedy, Albuquerque, University of New Mexico Press, 1958, p. 56.

12 Véase Mackenzie, Francisco de Rojas Zorrilla..., pp. 49-52.
} 
a mi error servirle quieren

de silvestre sepultura.

¡Quién de sí mismo pudiera

huirse!

(El Caín de Cataluña, p. 286a)

A diferencia de No hay ser padre siendo rey, el fratricida es aquí el menor de los hermanos, lo que da ocasión a sus airadas quejas, unas veces, generales y abstractas (“iQue sea yo el abatido/ porque he nacido después!”, p. 281b), y otras, más concretas:

Siempre han de echar los segundos

a las balas; los primeros

¿no le han de ver una vez

siquiera la cara al riesgo?

(El Caín de Cataluña, p. 275a)

Estas protestas, que podrían dar sentido al personaje, pierden eficacia dramática porque se trata de un díscolo impenitente que, compulsivamente, quiere todo lo que destinan a su hermano, sean riesgos o seguridades, sea una infanta $\mathrm{u}$ otra.

Frente a lo accidental del fratricidio en No hay ser padre siendo rey, en El Caín de Cataluña Berenguel busca, consciente e incansable, la muerte de Ramón y para ello reúne en su mente enferma ofensas y agravios imaginarios que lo atormentan:
Ahora para que el dolor
mío a derramar se atreva
de mi hermano y mi enemigo
la sangre, primero estrena
su voracidad en mí...
(El Caín de Cataluña, p. 283c)

\begin{abstract}
Al acabar el segundo acto, como en todas las tragedias de la serie que analizamos, el asesinato está consumado. El tercero se ha de dedicar al proceso penal contra el criminal. A diferencia de lo que ocurre en No hay ser padre siendo rey, el infante no da muestra alguna de arrepentimiento sino de desesperado orgullo, bajo el que se esconde la sicótica convulsión del sentimiento de culpa:
\end{abstract}




\section{BERENGUEL. No quiero misericordia. [...] \\ Muera yo como Caín \\ y por hierro.}

(El Caín de Cataluña, p. 288b)

Como en El marqués de Mantua, el rey deja la justicia en manos de un tribunal (los conselleres); pero, a diferencia del enérgico y decidido Carlomagno, pide también un dictamen sobre la posibilidad moral de la indulgencia.

Aquí el pueblo, en revuelta sediciosa, clama por el castigo del culpable. Por eso el conde, a pesar de su trágico pero sustancial acuerdo con esta demanda, ordena reprimir a los cabecillas:

CONDE. El pueblo honrado y fiel, por que a piedad no me obligue, me ha pedido que castigue a mi hijo Berenguel; y si no arguye malicia, es una lealtad muy fea juntarse el pueblo, aunque sea para pedirme justicia. Y así desde luego os mando...

MARQUÉS. Yo ya espero que me deis la orden.

CONDE. ...que castiguéis

a la cabeza del bando.

(El Caín de Cataluña, p. 289b)

Lo que teme el soberano es un linchamiento popular del fratricida. Precisamente, las medidas para impedirlo van a provocar - ironía trágica - la muerte del príncipe.

En este caso, el conde barcelonés no abdica, pero se presenta en la prisión en que está recluido Berenguel para facilitarle la huida. El fatum trágico dispone que la guardia, puesta para proteger al preso, dé la voz de alarma, creyendo que asaltan la cárcel:

GUARDA $1^{\circ}$. ...Salid, que han escalado las tapias y han entrado en el jardín los populares.

(El Caín de Cataluña, p. 293a) 
Disparan sobre el fugitivo "y cae en el tablado", con lo que se cumple la inexorable justicia y el aciago destino que pesaba sobre Berenguel.

\section{EL PRÍNCIPE CRISTIANO: DE LA FILOSOFÍA POLÍTICA A LAS TABLAS}

Entre las cuatro obras se observan a simple vista indudables semejanzas - que en tres de ellas (la de Guillén de Castro y las de Rojas Zorrilla) apuntan a una clara filiacion - y también variaciones y contrastes cuyo análisis puede revelar algo sobre la evolución de la comedia y de las ideas políticas en los cuarenta años que median entre las postrimerías del reinado de Felipe II y el apogeo del de su nieto Felipe IV.

Las cuatro giran en torno a la monarquía y su sentido. Subyacen, en lo sustancial, las doctrinas que derivan del De regimine principum escrito e inspirado por santo Tomás de Aquino. Como es sabido, los principios allí sustentados se retomaron en la España del siglo XVI y en otras naciones europeas para oponerlos a la moderna "razón de estado", expuesta por Maquiavelo en El príncipe. En esta campaña contra el florentino le cabe un lugar de honor a nuestro padre Pedro Ribadeneyra y su Príncipe cristiano, o sea, Tratado de la religión y virtudes que debe tener el principe cristiano para gobernar y conservar sus estados. Contra lo que Nicolás Maquiavelo y los políticos de este tiempo enseñan, que vio la luz de las prensas en 159513. Quizá no sea ocioso recordar que la obra se imprime en Madrid, en la imprenta de Pedro Madrigal, con la que Lope tendrá una fructífera relación unos años más tarde, y a costa del librero que se encargará de vender los primeros libros del poeta y dramaturgo: Juan de Montoya.

Si atendiéramos a las fechas precisas de la aparición del Tratado... de Ribadeneyra (la tasa es de 29 de noviembre de 1595), estaríamos tentados de imaginar que Lope escribió El marqués de Mantua bajo su directa e inmediata influencia, ya que, como se ha señalado, el drama se terminó y dató el 10 de enero de 1596.

No es rara tanta premura en un dramaturgo que tenía que alimentar la voraz máquina de los corrales de comedias y que, ya en plena vejez, redactó su obra maestra, El castigo sin venganza, en poco más de un mes. Además, precisamente por ese ritmo vertiginoso del teatro y de la creación toda del Fénix, parece que, en algunos casos, los motivos de inspiración son rápidas ojeadas a libros contemporáneos o noticias de última hora.

Con todo, en El marqués de Mantua, como en el resto de las tragedias que aquí comentamos, la machacona insistencia de Ribaneyra en el papel de la

13 Manejo la edición de Buenos Aires, Sopena Argentina, 1942, con introducción de Ignacio Puig S. J. 
iglesia y de la religión y en la subordinación del poder civil al eclesiástico, queda en un segundo plano. Claro está que ni a Lope ni a Guillén de Castro ni a Rojas se les ocurre discutir el relieve de la religión y sus principios en la vida social. El monarca justo y respetable sigue los criterios de la recta moral y esa recta moral la fija y determina la iglesia; pero no se sugiere dependencia alguna del poder clerical. Antes bien al contrario: contradiciendo a santo Tomás y al padre Ribadeneyra, presentan un poder civil que recibe directamente de Dios su carisma. El rey de Hungría tiene muy claro que él es el depositario de la justicia divina:

REY. $\quad$...de Dios es la justicia que ejercito, suya es la fuerte y cortadora espada, en mi mano por él desenvainada.

(La justicia en la piedad, p. 150b)

Y en El Caín de Cataluña nos encontramos con una tan directa expresión de la vinculación de la monarquía con la divinidad, que raya en lo sacrílego:

LEONOR. [Al rey. $]$ Si te llaman Vicedios los que en su lugar te ven...

(El Caín de Cataluña, p. 290a)

El mismo giro lo había usado unos años antes Calderón, pero - buen discípulo de los jesuitas - para aplicarlo al papa. En La cisma de Ingalaterra (por cierto, basada en otra obra del padre Ribadeneyra: Historia eclesiástica del cisma del reino de Inglaterra) leemos, referido a Julio II: "es Vice-Dios en su iglesia" (v. 56); "el pontífice es Dios" (v. 1963); "el papa es Vice-Dios, todo lo puede" (v. 1753) ${ }^{14}$.

En Rojas, el rey ha desplazado al papa en esa función de representante de Dios en la tierra. Como tal, reparte las funciones que han de cumplir los brazos de su reino:

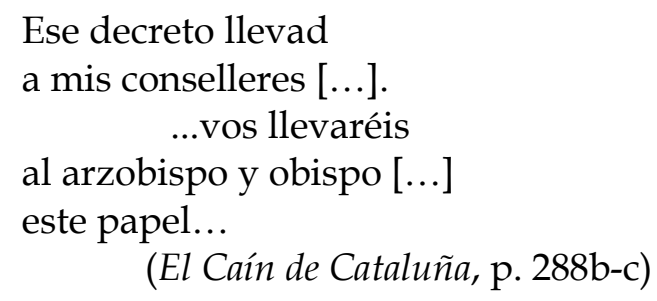

14 Cito por la edición de Francisco Ruiz Ramón, La cisma de Ingalaterra, Madrid, Castalia, 1981. 
Y se reserva la última decisión:

Uno y otro parecer

quiero ejecutar $\mathrm{y}$, conforme

lo más justo, obrar después...

(El Caín de Cataluña, p. 288c)

A pesar de la probable dependencia de El marqués de Mantua respecto a El príncipe cristiano, en el drama la iglesia no tiene más papel que el consuelo que presta "un venerable cartujo" a Valdovinos en su agonía y a Carloto en el momento de subir al cadalso.

\section{LAS IDEAS DE MARIANA Y LA ESCENA}

Los dramaturgos, aunque no se lo propusieran, son mucho más laicos que el padre Ribadeneyra. Las ideas políticas y jurídicas que subyacen en El marqués de Mantua están próximas a la obra de otro jesuita: De rege et regis institutione de Juan de Mariana15. Es cierto - no podía ser de otro modo- que Mariana dedica algunos capítulos a defender las prerrogativas de la iglesia: “El príncipe no puede legislar en materia de religión" (libro I, cap. X), “De la religión" (libro II, cap. XIV), “De los obispos" (libro III, cap. II), "No es verdad que puedan tolerarse otras religiones" (libro III, cap. XVII); pero su atención se centra en la buena marcha de la sociedad civil y no en la preeminencia del poder eclesiástico. Incluso cuando lamenta que haya decaído el poder de los obispos y pide un fortalecimiento del mismo (libro I, cap. IX), lo hace por razones puramente sociopolíticas, no teológicas:

no es mala medida de prudencia que las cabezas más importantes del reino tengan grandes recursos y un gran poder, con una amplia jurisdicción sobre muchos lugares y fortalezas, y no solo los nobles del reino, sino también los obispos, como ministros y guardianes del bien público, como exige su patriotismo y el orden sagrado que han recibido, y como se ha comprobado por la experiencia en sus intervenciones en apoyo de la justicia, defensa de la patria y cuidado de la religión. Con ello nadie se atreverá a amenazar el bien público. ${ }^{16}$

\footnotetext{
15 Para las citas de De rege et regis institutione utilizaré la traducción de Luis Sánchez Agesta, La dignidad real y la educación del rey, Madrid, Centro de Estudios Constitucionales, 1981. Esta traducción parte de la primera edición de 1599, pero intercala en el tercer libro el cap. VIII “De la moneda", que se añadió más tarde.

${ }^{16}$ Mariana, La dignidad real..., p. 102.
} 
Si es muy verosímil que Lope leyera o al menos hojeara el libro de Ribadeneyra, resulta menos probable que tuviera acceso a la obra de Mariana, no publicada hasta 1599 y en latín.

Es verdad que, según todos los indicios, Lope, como su álter ego el Fernando de La Dorotea, manejaba discretamente el latín; otra cosa es que se inclinara a leer espontáneamente las obras contemporáneas escritas en esa lengua.

Respecto a la fecha, no hay que olvidar que en De rege et regis institutione se señala el otoño de 1590 como fecha de redacción del tratado ${ }^{17}$. No sería imposible que el poeta tuviera noticias de su contenido cuando aún permanecía manuscrito pero, probablemente, se había difundido entre los círculos aristocráticos y cortesanos.

El tono y los centros de interés de El marqués de Mantua están mucho más cerca de los postulados de Mariana que de los de santo Tomás o Ribadeneyra. Sobre todo porque De rege..., como es bien sabido, desarrolla con amplitud y claridad poco comunes asuntos ya apuntados por santo Tomás, por Bodino, por Ribadeneyra y otros muchos: el derecho de resistencia y el tiranicidio.

Ribadeneyra explica sintética pero contundentemente "la diferencia que hay entre el rey y el tirano" en la parte final del cap. IX del libro II de El príncipe cristiano: "El verdadero rey está sujeto a las leyes de Dios y de la naturaleza; el tirano no tiene otra ley sino su voluntad"18.

Mariana dedica tres capítulos del libro I (V, VI y VII) a la figura del tirano y el tiranicidio, y otros tres a señalar los límites y mecanismos para impedir que el rey pueda convertirse en un tirano (VIII, IX y X). Sus fuentes son las mismas que las de Ribadeneyra y no pueden sorprender las coincidencias entre ambos; pero en Mariana todo es más laico y más moderno y, aunque no renuncia a ejemplos de las Sagradas Escrituras, prefiere los de la historia humana y política que tan bien conocía.

Véase cómo rescribe la doctrina antes citada de Ribadeneyra:

Un príncipe no debe creerse nunca dueño del estado ni de sus súbditos por más que los aduladores se lo susurren al oído, sino un gobernante al que los ciudadanos han asignado unos recursos, cuya cuantía no debe nunca aumentar sino por el consentimiento de los mismos pueblos. ${ }^{19}$

\footnotetext{
17 La dignidad real..., libro III, cap. XII, pp. 380-381: “Estaba esforzándome en concluir y corregir este libro, que empecé durante el descanso del verano, cuando una enfermedad inoportuna nos hizo caer en cama a todos los que vivíamos en aquel retiro solitario. [...] No dejará de ser memorable como pocos el otoño del año 1590".

${ }^{18}$ Ribadeneyra, El príncipe cristiano, p. 119a.

${ }^{19}$ Mariana, La dignidad real..., libro I, cap. v, p. 64.
} 
Sus argumentos se sustentan sobre un razonamiento moral, no teológico. Se hace eco de las teorías tomistas sobre la tiranía ab origine, por falta de legitimidad; pero lo que le interesa es la tiranía por el ejercicio torticero del poder (ex parte exercitii). En ella ve una depravación moral:

Muchas veces el tirano arrebata el poder mediante la fuerza, pero, aun partiendo de origen legítimo, degenera en todo género de vicios, principalmente en la codicia, la crueldad y la avaricia. ${ }^{20}$ comentamos:

Y describe con puntualidad los motivos centrales de los dramas que

el tirano [...] hace consistir su mayor poder en la libertad para entregarse sin freno a sus pasiones, no cree indecorosa ninguna maldad, comete todo género de crímenes, destruye la hacienda de los poderosos, viola la castidad, mata a los buenos y no hay una acción vil que no cometa a lo largo de su vida. ${ }^{21}$

Pues bien, este Mariana, encarnizado enemigo del teatro en esta misma obra (libro III, cap. XVI: "De los espectáculos"), vendrá a coincidir en los menores detalles de sus ideas políticas con los dramaturgos de la época y, muy especialmente, con el Lope que ronda los treinta y cinco años cuando redacta $E l$ marqués de Mantua.

\section{CARLOTO O LA RUPTURA DEL PACTO POLÍTICO}

Lope nos presenta un tirano en ejercicio: el heredero de la corona, Carloto. Sus pretensiones ilegales sirven para exponer, en boca de Rudolfo, la doctrina pactista desarrollada en De rege et regis institutione:

CARLOTO. ¿No puede el rey hacer ley?

RODULFO. Puede; del reino a su instancia.

CARLOTO. Hago ley que esta sea mía.

RODULFO. Esa no es ley, aunque es gusto, sino injusta tiranía.

(El marqués de Mantua, p. 227)

Este príncipe, legibus solutus, que no se somete a las leyes, sino que pretende crearlas a su capricho, sin concurso de la comunidad, se despeña hacia el crimen (el asesinato de Valdovinos), pero topa con el poder legítimo de su

20 Mariana, La dignidad real..., libro I, cap. V, p. 61.

${ }^{21}$ Mariana, La dignidad real..., libro I, cap. V, p. 61. 
padre, Carlomagno. El emperador, como depositario de la autoridad colectiva, lo somete a proceso, en el que no actúa directamente sino a través de un consejo, que juzga y condena a muerte al criminal. La esperanza de la impunidad, que alentó el delito, se desmorona ante un rey que sabe que "el príncipe no está dispensado de guardar las leyes", como reza el rótulo del cap. IX del libro I de Mariana. Es el propio monarca el que se enfrenta a la sedición, encarnada en Roldán. El paladín amenaza con el motín popular y es desterrado de inmediato:

ROLDÁN. EMPERADOR.
Amigos tiene el príncipe.

Salíos luego de París al punto ¿Qué es esto? y en seis años no entréis en él.

(El marqués de Mantua, pp. 356-357)

El príncipe es, en efecto, decapitado "como la espiga cae/ madura en el mes de julio" (p. 359). El drama de Lope ofrece la imagen del monarca absoluto, es decir, de aquel que monopoliza la acción de la justicia, a la que se someten todos los miembros de la comunidad, incluido el propio soberano. Por eso puede decir en la escena última:

EMPERADOR. Ya, conforme a las leyes y el proceso, hice justicia y vos tenéis venganza.

(El marqués de Mantua, p. 360)

El estado moderno, que es absoluto, sustrae a los particulares el derecho de vengarse; pero se ha de comprometer a satisfacer sus quejas, siempre "conforme a las leyes y el proceso", y a vindicar los crímenes de que hayan sido víctimas.

Esto se escribe en las postrimerías del reinado de Felipe II. Los contemporáneos pudieron ver en el Carlomagno dramático una contrafigura del rey prudente. No hay que olvidar que en la realidad histórica un heredero de la corona española había muerto confinado en el castillo de Arévalo. Don Carlos, el primogénito de Felipe II, falleció el 24 de julio de 1568. No parece haber duda sobre los trastornos sicofísicos del príncipe, pero también es cierto que en su insania fantaseó con huir a los Países Bajos, probablemente con la intención quimérica de hacerse fuerte junto a los descontentos con la política de su padre $^{22}$.

\footnotetext{
22 Véase un resumen riguroso y ameno del complejo caso del príncipe don Carlos en Geoffrey
} Parker, Felipe II, Madrid, Alianza, 1984, $3^{\text {a }}$ ed., pp. 114-123. 
Podría pensarse que, en una operación de damnatio memoriæ, la figura de don Carlos estaría enteramente olvidada en 1596. Es obvio que no fue así. Mariana, en De rege et regis institutione, habla paladinamente de la necesidad de despojar de sus derechos al primogénito cuando "se haya manchado con crímenes o se hayan apurado todos los medios para corregirle"23; y, entre ejemplos bíblicos, aparecen los casos de la historia patria:

así lo hizo en tiempo de nuestros abuelos el rey de Aragón don Juan II, y en nuestro tiempo tu padre [el del futuro Felipe III], los cuales han desheredado, uno y otro, a su primogénito Carlos. ${ }^{24}$

Carlomagno en el drama, Felipe II en la historia próxima someten a su primogénito a la ley general y no toleran sediciones en su apoyo.

\section{DEL REY ABAJO...}

Sin embargo, la consolidación de la monarquía absoluta, cuyo rasgo más definitorio es el del sometimiento de todos los miembros a la autoridad de un único poder jurisdiccional, engendra una curiosa paradoja, que va a tener su inconsciente reflejo en el largo discurrir de la comedia nueva.

Para crear el estado moderno, el que se reserva el monopolio de la violencia, según leyes y procedimientos previamente establecidos, se necesita la sacralización de la persona que representa ese poder excluyente. Se tiende a convertir al rey, contra el criterio de Mariana, de Ribadeneyra y de santo Tomás, en una figura intocable, en algún sentido por encima de las leyes. Su importancia para la vida social como garante de la paz y los derechos es tal que conviene exentarlo de cualquier servidumbre. Un drama atribuido, mal atribuido probablemente, a Rojas Zorrilla vendrá a sintetizar en términos poéticos ese sentimiento: Del rey abajo, ninguno. No hay en ese título una rendida adoración a la monarquía, que convertiría los agravios en honores y los atropellos en dádivas, sino una conciencia crítica de los posibles crímenes reales que, a pesar de serlo, no deben ser contestados ni juzgados porque la paz pública es un valor superior al dolor individual. A cambio, nadie, salvo la institución que encarna al estado, está exento del cumplimiento de la ley.

${ }^{23}$ Mariana, La dignidad real..., libro I, cap. IV, p. 49.

${ }^{24}$ Mariana, La dignidad real..., libro I, cap. IV, pp. 49-50. 


\section{RECONSIDERACIÓN DE LAS TESIS SOBRE EL TIRANICIDIO: DE MARIANA A GUILLÉN DE CASTRO}

Cuando Guillén de Castro escribe La justicia en la piedad, se ha cometido el atentado que costó la vida a Enrique IV de Francia, y el libro de Mariana ha sido quemado públicamente en París. Si el testimonio de Lope es representativo, parece que los ingenios españoles no se preocuparon especialmente por el magnicidio:

De la muerte del rey francés no se me entiende mucho, porque, entre otros desatinos míos, nunca creí que había reyes en otras lenguas. ${ }^{25}$

Este gran rey mereció grandes alabanzas, por cierto; pero a nosotros no nos pone tanta obligación, que no sea mayor la que tenemos a la verdad y a la patria... ${ }^{26}$

Con todo, después de lo ocurrido en París, la abierta aunque matizada aprobación del tiranicidio contenida en el libro de Mariana hubo de merecer una honda reconsideración.

No hace falta recordar que los dramaturgos no se dedican a la filosofía política y los más no se interesan ni poco ni mucho por esa ciencia; pero viven, como su público, en sociedad y no pueden dejar de verse afectados por los estados de opinión, los valores y prejuicios del momento en que escriben. A veces, incluso tratan de moldear con sus obras las ideas políticas y sociales de su auditorio ${ }^{27}$.

Quizá por seguir esta corriente social, necesitada de reforzar la autoridad real y de poner sordina a las peligrosas especulaciones sobre el tiranicidio, las comedias trágicas de Guillén de Castro y Rojas Zorrilla cambiaron significativamente la solución final ofrecida en El marqués de Mantua. En las tres, el prestigio de la monarquía parece extenderse del rey a su heredero, que se convierte en una figura intocable.

En La justicia en la piedad Guillén de Castro presenta a un rey tiránico ${ }^{28}$, no solo porque comete atropellos y crímenes sino fundamentalmente porque sostiene una errada interpretación del sentido del poder:

${ }^{25}$ Lope de Vega, Epistolario, ed. de Agustín González de Amezúa, Madrid, Real Academia Española, 1935-1943, tomo III, p. 23.

${ }^{26}$ Lope de Vega, Epistolario, tomo III, p. 25.

27 En cualquier caso, no parece que la comedia de Lope y sus discípulos fuera ese mecanismo propagandístico que imaginó José Antonio Maravall en su opúsculo Teatro y literatura en la sociedad barroca, Madrid, Seminarios y Ediciones, 1972.

${ }^{28}$ Un interesante estudio sobre la figura del "rey injusto y tirano" en el conjunto del teatro del poeta valenciano nos lo ofrece Gemma Domínguez Carvajal, Tipología de los personajes en la 
El ser rey ¿qué fuera en mí, si lo apenas deseado no facilitara ansí?

(La justicia en la piedad, p. 122b)

¿Qué es la muerte para mí?

El tener el gusto incierto, y más va en un gusto mío que en un millón de estas vidas.

(La justicia en la piedad, p. 124a)

Los octosílabos parecen una glosa a contrario de la corriente doctrinal que desemboca en Mariana:

Diréis que la felicidad estriba en hacer lo que se quiere, pero más bien es una desdicha hacer lo que no está permitido, y más miserable aún que se pueda hacer lo que es injusto. ${ }^{29}$ inevitable:

La consecuencia de los errores de principio del rey de Hungría es

$$
\begin{aligned}
& \quad \text { no solo [...] } \\
& \text { no asiste al gobierno [...]; } \\
& \text { mas las vidas no perdona } \\
& \text { ni las honras, y en su pecho } \\
& \text { nunca la humana piedad } \\
& \text { halló seguro aposento. [...] } \\
& \text { De todo lo cual resulta } \\
& \text { tanto alboroto en su reino, } \\
& \text { tal mancilla en su opinión, } \\
& \text { tan grande aborrecimiento } \\
& \text { de su persona en los suyos, } \\
& \text { que me anuncia un mal suceso. } \\
& \quad \text { (La justicia en la piedad, pp. 120-121) }
\end{aligned}
$$

Las quejas de Arcinda apelan al pueblo de Hungría para que satisfaga su agravio: "considerando/ que ha dejado de ser rey/ un rey en siendo tirano"

dramaturgia de Guillén de Castro y Bellvís (1569-1631), tesis de doctorado, Universidad de Barcelona, 2005, pp. 485-536.

${ }^{29}$ Mariana, La dignidad real..., libro I, cap. IX, p. 114. 
(p. 130b); pero la vergüenza del inicuo asesinato y la conciencia del rechazo colectivo regeneran a este monstruo irresponsable, y con ello el dramaturgo se ahorra el tener que condenar al rey en escena. El conflicto se traslada al primogénito.

Al acabar la primera jornada, el monarca, hasta ahora tiránico, trata de restañar las heridas en una suerte de amnistía que se otorga a sí mismo y a su hijo; pero los nuevos crímenes del príncipe obligan a dirigir contra él la máquina de la justicia absolutista, que no conoce excepciones.

El heredero sueña con privilegios que el dramaturgo quiere declarar abolidos:

$$
\begin{array}{ll}
\text { PRÍNCIPE. } & \text { En los hombres como yo } \\
& \text { ¿tienen su rigor las leyes? } \\
& \text { ¿Así castigan los reyes } \\
& \text { a sus herederos? No. }
\end{array}
$$

(La justicia en la piedad, p. 154b)

El poeta se propone desmentir al príncipe y lanzar un mensaje contra la impunidad; pero la sacralización de las personas reales ha avanzado considerablemente en los veintitantos años que median entre El marqués de Mantua y La justicia en la piedad. En la España de Felipe III, el poeta y su público parecen sentir la necesidad de perdonar al criminal conculcando la justicia poética o, mejor dicho, creando una justicia poética mucho más condescendiente e inconsecuente. Aquí triunfa la sedición que impone al rey, alborozado por el fracaso político que le permite salvar la vida de su hijo, la impunidad para los delitos de las personas reales.

\section{EN LA DÉCADA DE 1630: ROJAS ZORRILLA}

Más complejo es el caso de las tragedias de Rojas Zorrilla, entre otras razones porque los asesinatos se han convertido en fratricidios y afectan a la propia familia real y no a terceros. Tanto en No hay ser padre siendo rey como en El Caín de Cataluña la trágica obligación de impartir justicia recae sobre monarcas sabios y un punto condescendientes con estos hijos díscolos e ingobernables, a los que en vano intentan trasmitir las normas de buen gobierno, en la tradición del príncipe cristiano. En las dos obras encontramos la idea senequista del rey como siervo de la república, cuya vida está plagada de invencibles dificultades. Un juego de oxímoros expresa el peso fatigoso del poder: 
RAMÓN.

Ya veo

que es la corona un alivio

muy pesado; es un trofeo

muy costoso; es un adorno

que aflige al que le trae puesto;

es una riqueza pobre,

un honrado menosprecio,

un vituperio alabado,

una lisonja con riesgo,

una libre esclavitud;

pues de la suerte que vemos

que a un esclavo le señalan

sobre la frente, poniendo

- por que se sepa quién es -

nombre o señas de su dueño,

así al rey - ¡fiera señal! -

sobre la frente se ha puesto

la corona, por que sepan

que es esclavo de su reino.

(El Caín de Cataluña, p. 274a-b)

El gobernante está irremediablemente expuesto a los pareceres más contradictorios y las malicias de las gentes:

No hay cosa bien hecha en él

que a los suyos lo parezca:

si es justo, cruel le llaman;

si es piadoso, le desprecian.

(No hay ser padre..., vv. 65-68)

Los hijos díscolos se caracterizan por la voluntad de hacerse con el poder. Frente a los hijos buenos (Ramón, Alejandro), que aceptan estoicamente su papel social, los rebeldes pugnan por adueñarse de él, a pesar de las sabias advertencias paternas:

el gobierno y la grandeza

no consiste en procurarla, sino solo en merecerla.

(No hay ser padre..., vv. 60-62) 
A diferencia de la obra de Guillén de Castro, los padres de Rojas Zorrilla son viejos y enfermos:

REY. Una silla me llegad, la gota me trae sin mí.

(No hay ser padre..., vv. 1-2)

CONDE. $\quad$...no puedo tenerme en pie.

(El Caín de Cataluña, p. 217b)

Esta debilidad contrasta con la energía destructora de los hijos malos, envidiosos enfermizos que alientan esforzadamente un odio y un rencor que, como en el caso de Rugero (No hay ser padre...), no siempre sienten:

RUGERO. (¡Que esté deseando abrazarle

y valga conmigo más

mi condición que mi amor!)

(No hay ser padre..., vv. 493-495)

El enfrentamiento mortífero entre los hermanos implica nuevas y más agudas complicaciones en la resolución de la justicia poética, pues el delito - si cabe - es más grave y las patéticas contradicciones de las figuras paternas son mayores. Como en el Génesis, el rey (imagen de la divinidad en esta exacerbada visión del primer absolutismo) pregunta a los asesinos por su hermano. Las réplicas de los fratricidas son paralelas y repiten el texto bíblico, bien conocido por los espectadores:

ToDos. Berenguel, ¿dónde queda tu hermano?

BERENGUEL. ¿Pues yo sé de él?

¿Soy yo su guarda?

(El Caín de Cataluña, p. 288b)

REY. ¿Y tu hermano?

RUGERO.

REY.

No sé de él.

RUGERO. ¿No lo has visto?

No lo he visto.

(No hay ser padre..., vv. 2319-2320) 
Hay una sutil diferencia: Berenguel sabe que ha matado a su hermano, mientras Rugero cree haber apuñalado al valido del rey, el duque.

El juez se ve desgarrado entre dos afectos:

si es hijo el ejecutor,

el inocente es tu hijo.

(No hay ser padre..., vv. 2607-2608)

Las resonancias bíblicas se encuentran también en las reflexiones del viejo conde de Barcelona:

$$
\begin{aligned}
& \text { un hijo de dos que tuve } \\
& \text { dio muerte al otro cruel; } \\
& \text { y para vengar al uno } \\
& \text { dos hijos he de perder. }
\end{aligned}
$$

(El Caín de Cataluña, p. 288c) ${ }^{30}$

Los deberes inconciliables del amor paterno y la justicia real se expresan con puntualidad en los versos finales de No hay ser padre...:

$$
\begin{aligned}
& \text { siendo solo padre, es fuerza } \\
& \text { como padre perdonarte } \\
& \text { y siendo rey no pudiera. [...] } \\
& \text { que, a ser yo rey, te quitara } \\
& \text { de los hombros la cabeza; } \\
& \text { pero, padre, te perdono. }
\end{aligned}
$$

$$
\text { (No hay ser padre..., vv. 3234-3259) }
$$

A pesar de la firme resolución de los dos soberanos de castigar el asesinato, hay dos circunstancias políticas diversas que presionan sobre el desenlace. En No hay ser padre... el rey está firmemente convencido de la aberración que supone el que el asesino ciña algún día la corona. Tan arraigada

\footnotetext{
30 Recuérdese el relato del Libro segundo de Samuel, 14, 4-7 (traducción de Marciano Villanueva): Entró, pues, donde el rey la mujer de Tecoa y cayendo sobre su rostro en tierra se postró y dijo: “¡Sálvame, oh rey!” El rey le dijo: “¿Qué te pasa?” Y ella contestó: “¡Ay de mí! Soy una mujer viuda. Mi marido ha muerto. Tu sierva tiene dos hijos. Se pelearon en el campo, no había quien los separase y uno hirió al otro y le mató. Y ahora se alza toda la familia contra tu sierva y dicen: 'Entréganos al asesino de su hermano, al que mató, y haremos desaparecer también al heredero.' Así van a extinguir el ascua que me queda y no dejarán a mi marido nombre ni superviviente en la tierra".
}

(Biblia de Jerusalén, Bilbao, Descleer de Brouwer, 1993) 
es su convicción que prefiere la behetría (una fórmula ácrata de organización social) a una monarquía manchada de la sangre fraterna:

Por esto a mi reino infiero
que le está mejor aquí
que él propio reine por sí,
que el gobierno de Rugero.

(No hay ser padre..., vv. 3107-3110)

Pero otras perspectivas de carácter ético (“yo no recojo esta sangre/ porque se derrame aquella", vv. 3149-3150, dirá Casandra) determinan un movimiento en favor de la clemencia. En esta acción se combinan los prudentes consejos del valido (al que quería asesinar Rugero, aunque por error matara a Alejandro):

Todos dicen que no puedes, aunque justiciero seas, dejarles sin heredero.

(No hay ser padre..., vv. 3197-3199)

y un motín popular. El rey, con una sensibilidad "democrática" impropia del siglo XVII, escucha la voz popular o sediciosa, según se mire, y actúa en consecuencia:

\section{El pueblo dice que vivas, y también su voz me enseña que no quiere que yo reine, pues deroga mi sentencia.}

(No hay ser padre..., vv. 3221-3224)

La abdicación, como en La justicia en la piedad, pone una ingeniosa y esperanzada solución al conflicto irresoluble entre deberes.

En El Caín de Cataluña las circunstancias políticas son otras. El conde no está solo en su afán justiciero. Sus vasallos mantienen que

aunque él [Berenguel] suceda en el derecho de su hermano, es contra piedad común que se componga una corona de un delito. [...] fallamos que debe ser degollado en público teatro, para escarmiento de príncipes tiranos y para que sea inmortal la justicia de los catalanes.

(El Caín de Cataluña, p. 290a) 
Frente a este razonamiento jurídico, el parecer de la iglesia guarda relación con los versos de Casandra (El Caín de Cataluña) citados más arriba:

considerando que no se recoge la sangre del señor don Ramón, que Dios haya, porque se derrame la que ha quedado [...], es nuestro parecer use de misericordia y le perdone.

(El Caín de Cataluña, p. 290a)

El pueblo pide justicia y muerte contra el fratricida, y el conde actúa como político cristiano, que sabe distinguir el plano terreno del divino:

CONDE. $\quad$ El pueblo es voz de Dios.

Dios manda que mi hijo muera. [...]

Ya que yo firmo el castigo,

que firme Dios el perdón.

(El Caín de Cataluña, p. 290a-b)

En las escenas finales vuelve a aparecer la contradicción entre los papeles de rey y padre. El monarca absoluto ha de seguir las leyes y la voz popular:

$$
\begin{aligned}
& \text { El pueblo } \\
& \text { dice que habéis de morir... } \\
& \text { (El Caín de Cataluña, p. 292a) } \\
& \text { El pueblo, banderizado, } \\
& \text { pide vuestra muerte... } \\
& \text { (El Caín de Cataluña, p. 292b) }
\end{aligned}
$$

El padre compasivo le facilita la huida, aunque ya sabemos que con infausto resultado. Así la obra puede retomar, con mayor exactitud y propiedad, el motivo del romance del marqués de Mantua recreado en su drama por Lope de Vega:

hasta vengar en Caín

la sangre de Abel tan santo.

(El marqués de Mantua, p. 331)

El que dio la muerte a Abel

ha muerto como Caín.

(El Caín de Cataluña, p. 293c) 


\section{EN CONCLUSIÓN}

Los cuatro dramas a los que hemos dedicado nuestra atención parecen revelar notables cambios en la mentalidad colectiva. En tiempos de Felipe II (ese rey al que cierta historiografía y ciertas creaciones poéticas han querido presentar como la encarnación del tirano), la justicia poética no se detiene ante las personas reales. Parece existir una notable coherencia entre las teorías desarrolladas por la tradición que desemboca en De rege et regis institutione de Mariana y el justiciero final del drama de Lope. En los reinados de los Austrias menores, el ajusticiamiento de un príncipe en la ficción dramática resulta mucho más problemático. Como he tratado de explicar, los dramaturgos se hacen eco de una paradoja política: la profundización en el absolutismo (que implica la supresión de regímenes excepcionales y de jurisdicciones especiales) impulsa, al mismo tiempo, la salvedad relativa a las personas reales, por ser garantes del ordenamiento jurídico general, incluso cuando a título individual lo conculquen. De ahí que Guillén de Castro (La justicia en la piedad) y Rojas Zorrilla (No hay ser padre...) salven a los príncipes asesinos a través de la acción revolucionaria del pueblo, que restaura a los herederos que han sido condenados en justicia por el propio monarca.

Cuando, extremando los perfiles del conflicto, el príncipe tirano carece de cualquier simpatía (lo que ocurre en El Caín de Cataluña), el dramaturgo deja el castigo $-y$, con él, la justicia poética - al inapelable juicio de Dios o del destino, sin manchar su pluma con la sangre derramada de una persona real. 